\title{
Situated Learning in Online Architectural Studio Education
}

\author{
Ece Buldan \\ Faculty of Architecture, Department of Architecture, Yaşar University, Izmir, Turkey
}

Received: April 30th 2021, Revised: May 31st 2021, Accepted: June 10th 2021.

Refer: Buldan, E., (2021), Situated Learning in Online Architectural Studio Education, Journal of Design Studio, V.3, N.1, pp 59-70, E. Buldan ORCID: 0000-0003-3068-6480,

DOI: $10.46474 /$ jds.930642 https://doi.org/10.46474/jds.930642

\begin{abstract}
The pandemic causes acceleration in the development of online education. Relatedly, instructors have started to transform already applied methods in studio education and have produced new teaching methodologies in remote education. Since the communication channel in the new system is exposed to a change that creates that open an area for the search of situated learning in terms of interaction among students and between students and instructors that is strongly associated with Vygotsky's theory of the zone of proximal development in which social interactions is emphasized in learning. In this paper, the components of situated learning will be reading through an online design studio in architectural education. The changing concept of studio culture will be inquired from the issues of the learning environment and situations executed after the shift from physical to digital encountering. Moving of design studio into the online environment brings particular changes to the two aspects of the studio culture, which are studio as a method and studio as an environment. In this respect, an online design studio will be examined as a contextual framework with the theory of situated learning.
\end{abstract}

Keywords: The zone of proximal development, situated learning, online education, architectural studio.

\section{Introduction}

The pandemic, COVID-19, has fastened the ongoing trend towards online education in the age of information. As a first reaction to this rapid change, instructors have tried to use known methods, which are used in face-to-face education. However, in some respect, applying these methods requires different research with the ingredient of the online studio environment. Because of that, in the first step, the main cause for this adaptation was reasoned as technological rather than educational (Johnson et al., 2016). Since the duration of distance education has been extended, the aim of the educational staff transforms from crisis management through education as well. In this process, using effective tools and methods, which are so important in online education to attract the students from a screen of the media, becomes a crucial part of the education more than traditional education. This complicated environment faced by student and instructors bring a different situation and requires reconstruction of knowledge more than usual and open a new research area to examine situated learning that needs re-construction of knowledge in different contexts following different interactions.

The key components, which define situated learning, are interaction among students and between students and instructors, authentic 


\section{Journal of \\ Design Studio}

v:3 n:1 July 2021

activities, contextual situations, and interactions with society and cultures. The base of it, in the learning environment, is argued by Lev Vygotsky (1978) that learning has proceeded through the social interaction of the individuals in the zone of proximal development. Improvement in this zone is associated with the internalization of individually mediated social interaction. From this point of view, situated learning differs from traditional learning methods, in which students encounter different situations related to the activity and its context and learn in more interactive ways.

In architectural education, being a special setting for education due to the characteristic of learning by doing, the studio environment provides a physical production area, in which students spend more time than regular class settings and the studio transforms into a sociospatial environment for the students and the instructor. Accordingly, the design studio includes various spontaneous encountering that could be integrated into education, indeed, as a part of education. However, with the changing ontology of spatial and social beings of the studio, distance learning in architectural studio education is needed to be some adaptations and changes. Besides the integration of the digital tools to sustain the studio education, being away from a social studio environment and lack of everyday sociality in the campus environment leads students to social isolation (Davies and Graff, 2005; McGuire, 2019; Smiley et al., 2020 in Yorgancioğlu, 2020) which restricts the students' zone of proximal development.

This paper aims to produce a critical reading based on the effects of social isolation through the studio culture. Indeed, understanding social isolations not only refers to the physical remoteness from the learning environment but also covers the lack of interaction of the students in the online learning environment held in different platforms. In this respect, while online design studio will be examined as a contextual framework within the learning environment and situations executed after the shift from physical to digital encountering, the theory of situated learning as a social learning theory will be used as a theoretical framework to understand the importance of the social interaction in education.

\section{Theoretical Framework: Situated Learning}

In the 1970s, the researches on education demonstrate a transformation by cognitive scientists to develop an intelligent tutoring system in artificial intelligence (Rumelhart, Bobrow and Collins, 1975; Sleeman and Brown, 1982; Wenger, 1988 in Saivyer and Greeno, 2009). Thereafter, in the early phases of the 1980s, the number of works was increased about cognition and learning, and learning was covered as an internal individual mental process. However, during the 1980s, social scientists began to inquire about the role of interaction in cognition and learning. Accordingly, it is recognized that the social arrangements, namely situations, are fundamental while defining what is learned (Saivyer and Greeno, 2009).

The term, situated learning was first used by Lave and Wenger (1991), based on Lev Vygotsky's (1962) zone of proximal development and as a critic of Brown's (1989) cognitive apprenticeship (Saivyer and Greeno, 2009). The zone of proximal development is introduced by Vygotsky (1962) as a social theory of learning that emphasizes the role of social interaction in individual cognition and learning capacity. According to his theory, each individual has the actual development level and potential development level. The distance between them is described as the zone of proximal development which occurs with the guidance of a more knowledgeable other (Vygotsky, 1978). The other critical point in this learning theory is, learning occurs socially, however, each needs to internalize the knowledge to conceptualize what s/he learned which could be used in other contexts. Because according to him, there is a difference between what is experienced and what is learned that an individual learns more than experienced situations with the internalization and conceptualization of the knowledge (Vygotsky, 1978). Application of knowledge occurs with the conceptualization of the idea, which is "mindful abstraction" extracted from the 


\section{Journal of \\ Design Studio}

v:3 n:1 July 2021

original idea and could be applied in the different context (Salomon and Perkins, 1989). Furthermore, the social developmental theoretical background of Vygotsky (1962, 1978) constructs the main argument of the situated learning. According to this theory, knowledge is reconstructed and deconstructed through the communication and exchange occurring between people and their social and cultural context (Billett, 1996). Action in these contexts defines the obtaining and applying of knowledge in everyday situations (Lave and Wenger, 1991). In the explanation of situated learning, Lave (1988) defines knowledge as a tool that is used following the situations and continues to store in the memory.

Similar to Lave and Wenger (1991) and Vygotsky (1978); Brown, Collins, and Duguid (1989) believe that to achieve meaningful learning, it should be embedded in its social and physical context. Namely, the interaction between learners, and learners and tools play an important role. Moreover, Brown et al. argue that the concept of abstract learning creates a gap between the knowledge and authentic context and prevents the application of the knowledge in real-life situations. Knowledge could have a changeable meaning according to the activities and situation. Relatedly, they produced the cognitive apprenticeship, which focuses on the process rather than the endproduct of learning. Accordingly, knowledge could be transformed from one situation to another (Brown, Collins, and Newman, 1989). Gee (1997) emphasizes the importance of cognitive apprenticeship that without the situated meanings, knowledge acquisition becomes too general or specific for usage.

Cognitive apprenticeship as a model for the situated learning is improved to the application of the learning in authentic practices in everyday life. In authentic apprenticeship, learners work with each other and the tutors to reach the same level (Lave, 1988; Lave and Wenger, 1991). In cognitive apprenticeship, learning realizes via activities, cultures, and contexts (Lave and Wenger, 1991). In terms of practices of the community, Lave and Wegner define it as legitimate peripheral participation.
This concept is improved as a critic of Brown's (1989) cognitive apprenticeship. In terms of legitimate peripheral participation, the newcomers of the community, observe the old members and begin to experience the culture every day and s/he came to the center from the periphery, namely transform from apprenticeship to master, by becoming himself/herself a more knowledgeable other.

Lave and Wegner have improved the situated learning with the background idea of “... learning all defined relative to actional context, not to self-contained structures" (Lave and Wenger, 1991: 15). They emphasize the situated character of communication and human understanding. This understanding creates a shift in which social engagements take the place of the individual cognitive process. The learning process is executed in the participation framework, rather than the individual mind. Namely, it is distributed among participants. An increase in participation refers to the production process. Getting skills is acquired during the process under the condition of legitimate peripheral participation, which is the crucial characteristic of the process. Behind it, Lave and Wegner believe that learning has an actional ground (Lave and Wenger, 1991). Moreover, in situated learning, what is learned is dependent on the situations in which it is learned (Lave and Wenger, 1991). In this respect, cognitive apprenticeship emphasizes that working on a task is easier than working on the same problem individually (Brown et al., 1989; Hansman, 2001). In some respect, situated learning also refers to experiential learning because, in the class environment, it is held by learning by doing (Hautemo, 2016). Moreover, since it is thought that the root of the situations are action base, experiential learning becomes stronger, as situated actions (Woolgar and Suchman, 1989)

\section{Contextual Framework: Online Design Studio and Studio Culture}

The design studio is a strong pedagogical tool in art and design education (Crowther, 2013). One of the most comprehensive definitions of the studio was done by Donald Schön (1983) that in the traditional environment of design 


\section{Journal of \\ Design Studio}

v:3 n:1 July 2021

education, students are assigned problems and they tend to solve them through the projects. In the process, while they are working on the projects, reflective practice, and a dialogue of thinking and doing, they learn how to design (Schon, 1983). In terms of learning, the studio includes observations, experimentations, crits, making, doing, and reflective thinking (Boling, 2016; Marshalsey and Sclater, 2020). In these processes knowing, thinking, and acting are executed within a reciprocal relationship. With these characteristics, it provides a unique setting in practice-based art and design education for experiential learning (Crowther, 2013).

Online Design Studio was improved as an alternative for physical studio education in the early 1990s as a branch of distance education (Nilsson, 2014). The first example was a twoweek project held by the collaboration of Hong Kong University, University of British Columbia, Harvard University, Harvard Graduate School of Design, Escola Tecnica Superior d'Arquitecture de Barcelona, and Massachusetts Institute of Technology. However, due to the level of improvement in communication technologies was not enough in those years, the project was improved mostly with asynchronous methods as e-mails, shared CAD files, and conference calls (Wojtowicz, 1995).

The movement of the design studio from the physical spatial environment to the online platforms creates a need to use digital tools to sustain ongoing methods as crits, learning by doing, and reflective learning. With the improvement in information and communication technologies, the software systems used in learning management systems become capable of applying traditional curriculum and methods. With the technological developments, text-based collaborative environments transformed into 3D virtual ones (Maher et al., 1999; Nakapan and $\mathrm{Gu}, 2011$ ). Accordingly, the emergence of global teams and acceleration in cultural interaction supports teaching design education virtually (Marshalsey and Sclater, 2020). In this respect, creating a collaborative environment becomes the hot topic since this online environment can collect people from different regions in a platform and enables them to work together. Namely, the time and space understanding is expanded with the online environment and digital tools.

After the gradual overcoming of technical difficulties encountered by students and tutors, the social aspects of the studio culture have been problematized. Although in the methodological dimension, the collaborative working environment is materialized, in the social level, the group members work on the different parts of the project, and relatedly, this situation leads to co-operation, which prevents the personal synergistic process between the individuals (Kvan, 2000). In terms of design education, similar to the remote working process, students apply the same method in the group works that different parts of the assignment are worked separately and at the end of the process they combine them. The whole process is carried out individually, getting advantage from other perspectives and mental development through sociality are executed at a minimum level due to the changing meaning of collaborative working. Although it is believed that the online studio fastens the independent learning process and encouraging the creation of meaningful knowledge (Krämer et al., 2015), students could less their way of learning in this too much freedom with the question of how and when they interact (Sun and Rueda, 2012). However, through reflective thinking, observations, and learning from each other in the physical studio environment, students can control their freedom and creates a reciprocal relationship between individual learning and interaction. Since online design studios separate students from the physical environment, it can lead to danger as detachment from the surroundings which means to elimination the socio-cultural reality of the studio environment (Achten et al., 2011). Accordingly, the detachment from the physical environment creates the first step for social isolation, which eliminates the spontaneous encountering of the physical environment. For example, students are always able to see others' projects in the studio environment and tend to observe and 


\section{Journal of \\ Design Studio}

v:3 n:1 July 2021

discuss them even at out-of-course times. It creates a working-based social area which is an unconscious natural setting rather than an already design place. However, in online working environments, at least at the first stage, there is a need for conscious studio design for communication.

The spatial learning environment of the studio provides a good opportunity for its users in terms of creating social interaction (Marshalsey and Sclater, 2020). Informally or formally, it is assumed as a collaborative working environment, in which students, instructors, or other members of the studio learn collaboratively (Boling, 2016; Vaughan et al., 2008). Moreover, as a learning environment, the studio could be assumed as a simulation of the real world with its sociability, culture, and spatiality (Schon, 1983). Based on the characteristic of the design studio, contextualization of the studio is done as the method of learning and the learning environment. These two characteristics of the studio are so integrated into each other to transform the knowledge in practical-based disciplines (Lynas, Budge, and Beale, 2013). Accordingly, Walter Wendler and Julia Rogers argue that a studio has a specific culture (1995: 326) "Design Life Space... ... address social, environmental, geographic, economic, and climatic parameters, to name a few. Context definition defines those parameters through which relationships of ideas and values are viewed and judged." Moreover, "The studio culture, defined by all participants as a mode of interaction around a discipline-specific subject, mimics the informal modes of acquiring, appropriating and sharing of knowledge of everyday social interactions" (Catina, 2020: 2). Relatedly, while studio culture is tired to integrate into online education, there is a need to work on the changing lifestyle in which adaptation problems to the virtual environment, the uncomfortable feeling among the foreign people, lack of socializing between students causes social isolation and prevents the success in studio education.

\section{Situated Learning in Online Design Studios}

Due to the COVID-19 pandemic, in social isolation, daily life practices of the students in the learning environment have been exposed to deep change that waking up and opening the computer has taken the place of going to campus for both education and sociality. The same situation reflects on architectural education that the studio environment as a social activity hub becomes physically inaccessible (Sun et al., 2020). This physical distance resulted in a decrease in social interaction, at least finding a different communication method. Even if they overcome the problem of interaction caused by physical remoteness, students rarely have a chance to meet those with who they do not familiar before distance education. The decrease in social interaction is elevated by the feeling of discomfort and difficulties in the online education platform. Therefore, some of the students pull themselves back more than they normally would. Although students may be in social isolation in physical learning environments, the possibility of finding themselves isolated in the online environment is higher since they are not exposed to a spontaneous interaction or being physically in a class environment. As a result, the interaction, which is already born difficulties, becomes more problematic. Since social interaction has the main importance in social learning theory, broadening the zone of proximal development is impeded. Because to extend the zone of proximal capacity for learning, individuals need to interact with other people.

By stating Vygotsky's zone of primal development, Strauss (1993) emphasizes the gap between potential and actual learning conditions. This gap fills and extended with the mediation, or internalization, of the social and cultural interaction. Interactions between the individuals have the role of "cognitive change catalysts" (Weibell, 2011: 136). In the online education process, students have difficulties creating a connection with their peers and instructors out of the course time and this situation directly affects their actual level of learning, relatedly proximal development. For 


\section{Journal of \\ Design Studio}

v:3 n:1 July 2021

example, an analysis done with first-year students of business degree demonstrates that although participation does not affect the passing grade, there is a significant difference between passing and failing students' participation. In all sections of the course, the participation level of failed students in the discussions is lower than those who follow the course by discussing (Davies and Graff, 2005). This researche done to understand the effect of social isolation on the grades and anxiety level of the students demonstrates its necessity.

Another critical point of the zone of development is the answer to what is learned is not an acquiring a piece of information, rather, it defines the new development level with the guidance of the instructor, as more knowledgable other (Strauss, 1993). Furthermore, in this understanding, the role of a more knowledgeable other is to increase the encouragement of students through independent learning (Moll, 1990). In this respect, for the achievement in situated learning practices, while the learner has the active role who directs the learning process, the instructor's role is one of the external interventions for an interactive learning environment. In terms of online education, the instructor needs to offer online media and different interaction models for deeper understanding and mediation of the knowledge in the cognition of students (Yarbrough, 2018). To transform the virtuality of online education into authentic activities, Herrington, Reeves, and Oliver (2006) suggest seven requirements in the tasks which need to be ill-defined, have sub-tasks, have larger periods, have different perspectives for achieving, apply in different areas, and collaboration and have different ways of solving and outcomes. Among them achieving different perspectives and work in collaboration could be the solution to prevent social isolation. To create a collaboration in online learning, preferring group works is more crucial than do that in regular education. Besides preventing social isolation, working with others make the student familiarize with the different perspectives and able to extend their zone of proximal development (Brieger, Arghode, and McLean, 2020). Since online education does not allow spontaneous encountering for knowledge exchange or social interaction as it happens in the physical class environment, organized spontaneity could achieve for filling this gap. Moreover, besides the prevention of social isolation, a well-organized online design studio supports the students' social interaction that includes people with different cultural backgrounds. The variety of participants can be increased and encountering different cultures and perspectives could be implemented to the studio (Rodriguez et al., 2018). For example, İstanbul Technical University organized a mixed studio for fourth and sixth-year architectural design studio students that include physical and virtual studio entitled IOKOKENT- a global multidisciplinary network on housing research and learning and held with the School of Architecture of Valencia, Spain, Lisbon University Institute, Portugal and Gebze Technical University, Turkey. In the project, group works were held to enable the communication of the students, and, 29 percent of the 45 comments expressed the need for more direct communication and group works with the international students, which makes the platform more interactive and real (Alkiser Bregger, 2017). On the other hand, in another case experienced with 617 students in the department of architecture from 15 universities in Jordan, 79.5 percent of the students express that group works are not effective and the quality of the production is limited in collaborative online education. Although they want to discuss their projects with peers and have an idea with other projects as a tutorial, working together on the online platform does not work (Alnusairat et al., 2020). Based on the examples, it is clear that students tend to learn other perspectives and awareness of the importance of the interaction, however, in the assignments they have difficulties coming together. Rather than offering a group assignment, in-class activities could be the solution to make meetings easier and creating an interactive environment without stress.

Active participation and being a part of group work should be supported, however, for those who continue to protect their silence during the courses, the online studio environment needs to 


\section{Journal of \\ Design Studio}

v:3 n:1 July 2021

offer something new for their achievement. Although active interaction is emphasized in both regular and online education, the role of passive participation in online learning communities cannot be ignored. For example, in the online graphic studio course held in Utah State University (USA), students were wanted to submit a post about the weekly lectures, and each student was required to respond to another two students' posts. This method that is used to increase students' interaction is to make them familiar with the other students' work. When students have an idea about the works of the others, their anxiety level about the course decrease (George, 2018). In an online design studio, students can follow the outputs of online tools such as discussion groups, tutorials, and forums. Michael Beaudoin (2002) indicates them as invisible students. Moreover, spending time at the online learning-related tasks of these students more than active participants. In passive, interaction with the tools becomes more important and students have passive interactions with the discussions or the works of other students. A large-scale study of 3000 students and 3 years, held at the School of Engineering and Innovation at The Open University (UK), emphasizes the importance of passive interaction. In the research, a positive correlation is viewed between students' visits to slots and success. Moreover, one of the students indicated that they can have a chance to making the right thing or not by comparing it with others' work (Jones et al., 2020). It is a positive part of online education that may not be sustained at face-to-face education. Students who feel uncomfortable at the synchronous discussions have a chance to integrate themselves into the legitimate peripheral participation at the minimum level.

However, these all researches also demonstrate that active interaction in an online environment has a bigger role than passive participation. Because, social presence is a necessity for teaching and cognitive presence to reach "higher-order thinking" (Armellini and De Stefani, 2016 in Jones, Lotz and Holden, 2020). Moreover, in the same research, a student expresses the importance of active interaction that distance education is difficult, and with the interaction, it becomes easier. Constructing a shared experience is a key element (Jones et al., 2020). Students can learn by themselves and increase their knowledge comprehension but without the assistance or guidance of peers or tutors cannot increase the potential development level.

Since the physical studio environment provides a setting for students to interact to work and discuss out of the studio course time, students need to be part of this kind of digital environment at distance education. Institutions' online learning management systems have a restricted background for it and students argue that in the system, they beware to share their ideas due to the hierarchical relationship between instructors and students. Referring to this system, to increase the direct interaction between students and students and tutors in distance education, WEB 2.0 tools, as social media has an important role to create a collaborative working environment (Rodriguez et al., 2018; Schnabel and Ham, 2013). Since the new generation of students is so familiar with these technologies and platforms, an adaptation of its use at the online studios increases the interaction between students (Ham and Schnabel, 2011). On the other hand, a combination of social media and search engines makes people decoders, rather than applying the knowledge within a different context (Mallgrave, 2010). In this respect, tutorials and assignments organized by the tutors have an importance that should be a focus on emerging the creative thinking mechanism of the students.

Schnabel and Ham (2013) argue the failure of the online management system in architectural education-learning digital due to the lack of connection with learning digital-social digital (Figure 1). Learning Management System (LMS) and socializing have a distinct border and are not connected. What they learn does not have a connection in their interaction in the social digital life, which prevents the internalization of the knowledge. They just get some knowledge during the course time and have an interaction out of the course, in which interaction is not over the knowledge achieved 


\section{Journal of \\ Design Studio}

v:3 n:1 July 2021

due to this border. However, engagement needs a central place for the construction of knowledge and architectural students should have an opportunity to engage with each other to support the design decision. In a design studio, there is a sharp borderline between the modes of communication and the learning environment that needs to be overcome. Furthermore, they indicate the importance of effective use of social networks, such as Facebook. Because it provides a two-way experience to the students which are acting as learners and researchers as making contributions on the related subject area (Schnabel and Ham, 2013). As experienced in the studio culture students socialize while working. In this respect, some parts of the interactions are focus on the design course. Because the working environment and the social environment are the same. However, in online education, this coordination could be easily changed by the students because it is a kind of preference, not a situation they are exposed to.
In order to create the studio culture in the online design studio, user-friendly platforms such as social media play an important role. In the research of Şule Tatli Pektaş (2015), a fiveweek collaborative project was held with two groups of students from different countries, for which students were responded to a green and sustainable building. After one week of traditional face-to-face education, students continue to study in an online studio environment. In the online studio part, besides learning management systems, a forum and Facebook page were integrated into the online studio and. As a result, students indicate that they feel more comfortable with Facebook while sharing their ideas since there is no hierarchy between instructors and them. Although the forum is a kind of informal part of the studio, it still becomes too formal for them. Moreover, apart from socializing, students use social media pages for discussions and sharing related documents about the project (Pektaş, 2015). It proves that students feel more comfortable in the online social environment

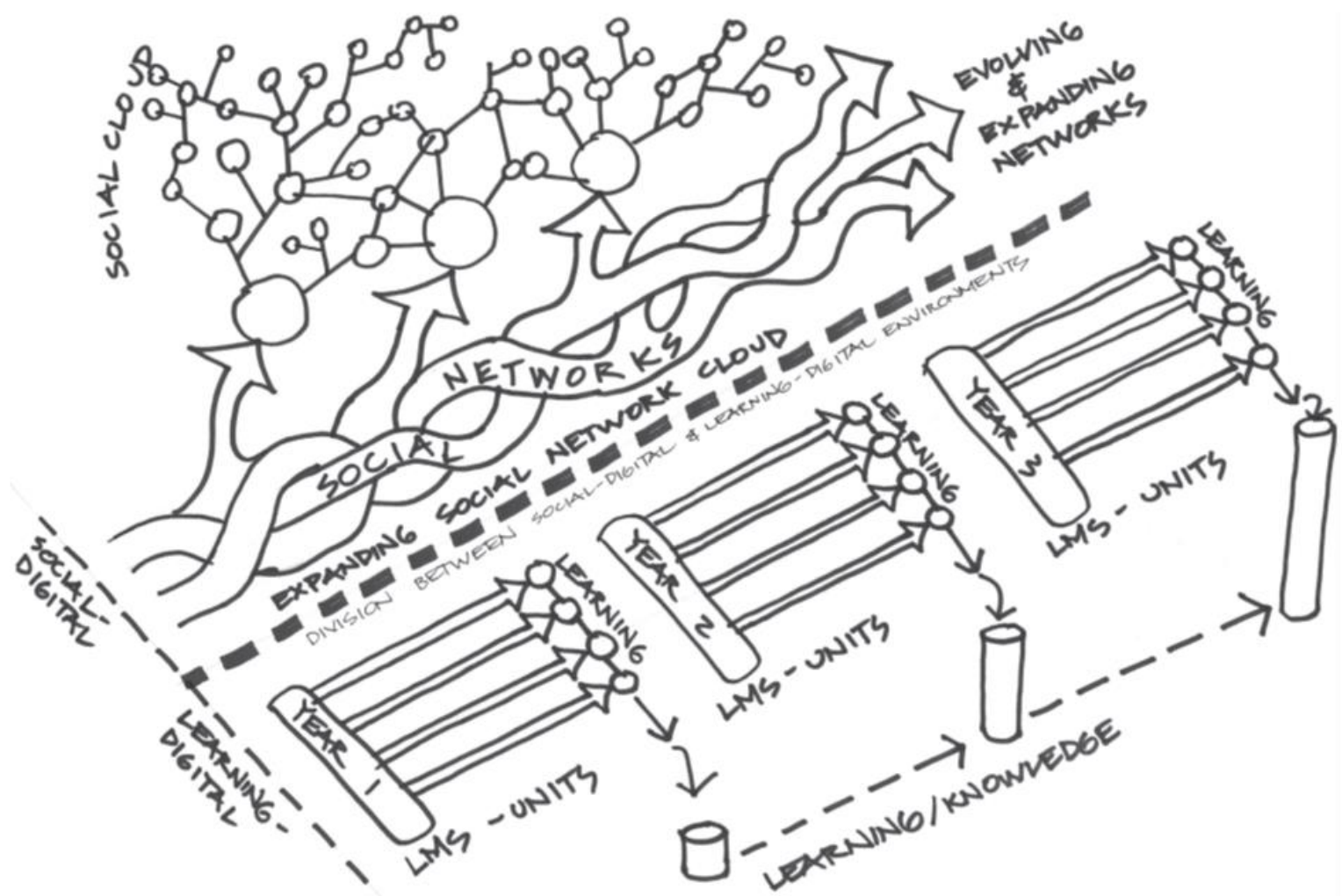

Figure 1: The division between learning digital and social digital (Schnabel and Ham, 2013) 


\section{Journal of \\ Design Studio}

v:3 n:1 July 2021

for interaction and knowledge exchange. While students are in the traditional design studio, spontaneous encountering, relatedly interaction with the others the out of the studio is does not need to be so integrated with the curriculum of the course. Or it is placed at the hidden curriculum. However, in the online studio environment, since students do not have this opportunity, there a need to integrate it with the social environment that includes professional practices and other perspectives. In order to create an authentic activity in an online environment, it should offer interactions different from conventional studio programs (Rodriguez et al., 2018). There is a need for mediation between learners and social aspects.

Another important part of online education is the issue of sustainability. Students' motivation and success are decreasing at the later stages (Jones et al., 2020). A social activity and social presence become more important in this part because they do not want to attend studios in which they cannot demonstrate their social existence. Moreover, the online design studio allows freedom to students in terms of management of their times and planning the learning process, and supports independent learning (Krämer et al., 2015). However, in legitimate peripheral participation, students are far away from the center, and independence of their knowledge acquisition should be increase gradually, not at the beginning of education. Relatedly, as mentioned above, in online education, students are supported for interaction to make them achieve an improvement in the zone of proximal development, internalization of the knowledge, and to prepare them to the level of independent learning.

\section{Conclusion}

Due to the pandemic, COVID-19, digitization has started to accelerate much more than ever before. In normal conditions, the development of technology and its adaptation through the environment will take between five and ten years. However, these days, these improvements took place just in a year. This allowed us to test the simulation of the future in real life. Although carrying education through the online platform has been executed, with the pandemic, educational institutions have to make it in just a short period.

Since design studios are based on the learning by doing approach and giving an unusual learning environment where is a social space as well, this adaptation process brings more difficulties than the other courses. It begins to lose its collaborative social environment, a Design Life Space (Wendler and Rogers, 1995). In this setting, appropriation, sharing, and acquiring knowledge occur informally but concerning the discipline-specific subject. Students' zone of proximal development extends its borders unconsciously. However, while this physical social setting is carried through the online platform, a lack of situated learning activities demonstrates itself. Motivation, success, relatedly grades of the students start to decrease. Without interactions, the students find themselves in an information pool and lost their excitement about the studio. They need to show their presence and have a relationship with the peers, tutors, information. Moreover, it is important to keep in mind that, the social settings of the students' change. In online education, their domestic environment intersects with the learning environment (Gül et al., 2012). And, re-construction of the knowledge is done with the domestic environment, not in the learning environment. They lost one of the biggest parts of studio culture in which subject-related discussions have a continuous flow.

From this point of view, the online studio environment is needed to be improved with the social settings. In studio education, gathering knowledge, and increase the elements of repertoire are so related to social interaction. Although social media or any other web tools support the students' development by opening an area for interaction to support situated learning, it cannot compete with spontaneous unconscious learning. Online education offers great opportunities in terms of creating an environment for interaction between different localities anywhere in the world. However, in the social dimension, this so-called togetherness does not operative. 


\section{Acknowledgments:}

I would like to thank Professor Fehmi Doğan for his comments and reviews.

\section{References:}

Achten, H., Koszewski, K. and Martens, B., (2011), What happened after the "hype" on virtual design studios?: some considerations for a roundtable discussion. CUMINCAD.

Alkiser Bregger, Y., (2017), Integrating Blended and Problem-Based Learning into an Architectural Housing Design Studio: A Case Study. Journal of Problem Based Learning in Higher Education 5(1). ERIC: 126-137.

Alnusairat, S., Al Maani, D., and Al-Jokhadar, A., (2020), Architecture students' satisfaction with and perceptions of online design studios during COVID-19 lockdown.

Armellini, A., and De Stefani, M., (2016), Social presence in the 21st century: An adjustment to the Community of Inquiry framework. British Journal of Educational Technology 47(6). Wiley Online Library: 1202-1216.

Beaudoin, M.F., (2002), Learning or lurking?: Tracking the "invisible" online student. The internet and higher education 5(2). Elsevier: $147-155$.

Billett, S., (1996), Situated learning: Bridging sociocultural and cognitive theorising. Learning and instruction 6(3): 263-280.

Boling, E., (2016), Studio Teaching in Higher Education. DOI: 10.4324/9781315697420.

Brieger, E., Arghode, V. and McLean, G., (2020), Connecting theory and practice: reviewing six learning theories to inform online instruction. European Journal of Training and Development 44(4/5): 321/339. DOI: 10.1108/EJTD-07-2019-0116.

Brown, J, S., Collins A and Newman SE (1989), Cognitive apprenticeship: Teaching the crafts of reading, writing, and mathematics. In: Knowing, Learning, and Instruction: Essays in

\author{
Honor of Robert Glaser. DOI: \\ 10.4324/9781315044408-14.
}

Catina, A., (2020), Dialogue and studio space: the architectural design studio as the setting for continuous reflection. Journal of Applied Learning \& Teaching 3(1). Simon Fraser University.

Crowther, P., (2013), Understanding the signature pedagogy of the design studio and the opportunities for its technological enhancement. Journal of Learning Design. DOI: $10.5204 /$ jld.v6i3.155.

Davies, J. and Graff, M,. (2005), Performance in e-learning: Online participation and student grades. British Journal of Educational Technology 36(4): 657-663. DOI: 10.1111/j.1467-8535.2005.00542.x.

Gee, J.P., (1997), Thinking, learning, and reading: The situated sociocultural mind. In: Situated Cognition Social Semiotic and Psychological Perspectives.

George, B.H., (2018), Drawing online: A comparative analysis of an online basic graphics course. Landscape Journal. DOI: 10.3368/lj.37.1.23.

Gül, L.F., Williams, A. and Gu, N., (2012), Constructivist learning theory in virtual design studios. In: Computational Design Methods and Technologies: Applications in CAD, CAM and CAE Education, pp. 139-162. DOI: 10.4018/978-1-61350-180-1.ch009.

Ham, J.J. and Schnabel, M.A., (2011), Web 2.0 virtual design studio: Social networking as facilitator of design education. In: Architectural Science Review, 2011, pp. 108-116. DOI: 10.1080/00038628.2011.582369.

Hansman, C.A., (2001), Context-Based Adult Learning Learning Outside the Mind. New Directions for Adult and Continuing Education.

Hautemo, A.M., (2016), Situated learning: A theoretical base for online learning wikipedia translation into Oshikwanyama at a Namibian 


\section{Journal of \\ Design Studio}

v:3 n:1 July 2021

school. The Eighth International Conference on Mobile, Hybrid, and On-line Learning Situated.

Herrington, J., Reeves, T.C. and Oliver, R., (2006), Authentic tasks online: A synergy among learner, task, and technology. Distance Education 27(2). Taylor \& Francis: 233-247.

Johnson, A.M., Jacovina, M.E., Russell, D.G., et al. (2016), Challenges and Solutions When Using Technologies in the Classroom. ERIC Clearinghouse.

Jones, D., Lotz, N. and Holden, G., (2020), A longitudinal study of virtual design studio (VDS) use in STEM distance design education. International Journal of Technology and Design Education. Springer: 1-27.

Krämer, B.J., Neugebauer, J., Magenheim, J., et al. (2015), New ways of learning: Comparing the effectiveness of interactive online media in distance education with the European textbook tradition. British Journal of Educational Technology 46(5). Wiley Online Library: 965971.

Kvan, T., (2000), Collaborative design: what is it? Automation in construction 9(4). Elsevier: 409-415.

Lave, J., (1988), Cognition in Practice: Mind, Mathematics and Culture in Everyday Life. Cambridge university press. DOI: 10.2307/2073537.

Lave, J., and Wenger, E., (1991), Legitimate Peripheral Participation. New York: Cambridge university press. DOI:

10.1017/cbo9780511815355.003.

Lynas, E., Budge, K., and Beale, C., (2013), Hands on: The importance of studio learning in design education. Visual Inquiry. DOI: 10.1386/vi.2.2.127_1.

Maher, M. L., Skow, B. and Cicognani, A., (1999), Designing the virtual campus. Design Studies. DOI: 10.1016/S0142-694X(98)00043$\mathrm{X}$.
Mallgrave, H.F., (2010), The Architect's Brain: Neuroscience, Creativity, and Architecture. John Wiley \& Sons.

Marshalsey, L. and Sclater, M., (2020), Together but Apart: Creating and Supporting Online Learning Communities in an Era of Distributed Studio Education. International Journal of Art and Design Education. DOI: 10.1111/jade. 12331 .

McGuire, S., (2019), Virilio, the "Infra" Urban and the Logic of Big Data. Media Theory 3(2): 121-132.

Moll, L.C., (1990), Vygotsky's zone of proximal development: Rethinking its instructional implications. Infancia y Aprendizaje 13(51-52): 157-168. DOI: 10.1080/02103702.1990.10822276.

Nakapan, W. and Gu, N., (2011), Preliminary experiments of opensim performance evaluation for virtual design studios. In: Circuit Bending, Breaking and Mending - Proceedings of the 16th International Conference on Computer-Aided Architectural Design Research in Asia, CAADRIA 2011, 2011.

Nilsson, F., (2014), Collaboration is not enough! What do architects and designers bring? In: Collaboration: Organising for design impact and value. Transdisciplinary Design Research Symposium 2014, 2014.

Pektaş, Ş.T., (2015), The virtual design studio on the cloud: A blended and distributed approach for technology-mediated design education. Architectural Science Review 58(3): 255-265.

DOI: 10.1080/00038628.2015.1034085.

Rodriguez, C., Hudson, R. and Niblock, C., (2018), Collaborative learning in architectural education: Benefits of combining conventional studio, virtual design studio and live projects. British Journal of Educational Technology 49(3): 337-353. DOI: 10.1111/bjet.12535.

Rumelhart, D.E., Bobrow, D.G., and Collins, A., (1975), Representation and Understanding: 
Studies in Cognitive Science. New York: Academic Press.

Saivyer, R.K., and Greeno, J.G., (2009), Situativity and Learning. In: The Cambridge Handbook of Situated Cognition.

Salomon, G., and Perkins, D.N., (1989), Rocky Roads to Transfer. Educational Psychologist.

Schnabel, M.A. and Ham, J.J., (2013), A framework for social networked architectural education. In: Open Systems - Proceedings of the 18th International Conference on Computer-Aided Architectural Design Research in Asia, CAADRIA 2013, 2013, pp. 313-322.

Schon, D.A., (1983), The Reflective Practitioner: How Professionals Think in Action (Arena).

Sleeman, D.H. and Brown, J.S., (1982), Intelligent tutoring systems. International Journal of Man-Machine Studies. DOI: 10.1016/S0020-7373(79)80002-4.

Smiley, D., Hirsch, A., Alday, I., et al. (2020), Field Notes on Pandemic Teaching: 4., Places Journal (2020). DOI: 10.22269/200421.

Strauss, S., (1993), Theories of Learning and Development for Academics and Educators. Educational Psychologist 28(3): 1919-203. DOI: $10.1207 / \mathrm{s} 15326985$ ep2803_1.

Sun, JC-Y., and Rueda, R., (2012), Situational interest, computer self-efficacy and selfregulation: Their impact on student engagement in distance education. British journal of educational technology 43(2). Wiley Online Library: 191-204.

Sun, L., Tang, Y., and Zuo, W., (2020), Coronavirus pushes education online. Nature Materials 19(6). Nature Publishing Group: 687.

Vaughan, S., Austerlitz, N., Blythman, M., et al. (2008), Mind the Gap: expectations, ambiguity and pedagogy within art and design higher education. In: The Student Experience in Art and Design Higher Education: Drivers for Change.

Vygotsky, L., (1962), Thought and Language Revised Edition. The Journal of Applied Behavioral Science.

Vygotsky, L., (1978), Mind in Society. DOI: 10.2307/j.ctvjf9vz4.

Weibell, C.J., (2011), Principles of Learning: A Conceptual Framework for Domain-Specific Theories of Learning. All Theses and Dissertations.

Wendler, W.V. and Rogers, J.S., (1995), The design life space: verbal communication in the architectural design studio. Journal of Architectural and Planning Research. JSTOR: 319-336.

Wenger, E., (1988), Artificial intelligence and tutoring systems: Computational and cognitive approaches to the communication of knowledge. Knowledge-Based Systems. DOI: 10.1016/0950-7051(88)90091-3.

Wojtowicz, J., (1995), Virtual Design Studio\}. Hong Kong University Press.

Woolgar, S. and Suchman, L.A., (1989), Plans and Situated Actions: The Problem of Human Machine Communication. Contemporary Sociology. DOI: 10.2307/2073874.

Yarbrough, J.R., (2018), Adapting Adult Learning Theory to Support Innovative, Advanced, Online Learning -- WVMD Model. Research in Higher Education Journal 35: 1-15.

Yorgancioğlu, D., (2020), Critical Reflections on the Surface, Pedagogical and Epistemological Features of the Design Studio under the "New Normal" Conditions. Journal of Design Studio 2(1): 25-36. 